\title{
Community Health Information and Tracking System (CHITS): Lessons from Eight Years Implementation of a Pioneer Electronic Medical Record System in the Philippines
}

\author{
Arturo M. Ongkeko, Jr., Randy G. Fernandez, Patrick G. Sylim, Abegail Jayne P. Amoranto, \\ Marie-Irene Ronquillo-Sy, Abby Dariel F. Santos, Jonathan G. Fabia and Portia H. Fernandez-Marcelo \\ National Telehealth Center, National Institutes of Health, University of the Philippines Manila
}

\begin{abstract}
The CHITS (Community Health Information and Tracking System), the first electronic medical record system in the Philippines that is used widely, has persevered through time and slowly extended its geographic footprint, even without a national policy. This study describes the process of CHITS development, its enabling factors and challenges affecting its adoption, and its continuing use and expansion through eight years of implementation (2004 to 2012) using the HOT-fit model. This paper used a case study approach. CHITS was developed through a collaborative and participative user-centric strategies. Increased efficiency, improved data quality, streamlined records management and improved morale among government health workers are benefits attributed to CHITS. Its longevity and expansion through peer and local policy adoption speaks of an eHealth technology built for and by the people. While computerization has been adapted by an increasing number of local governments, needs of end-users, program managers and policy-makers continue to evolve. Challenges in keeping CHITS technically robust, up-to-date and scalable are already encountered. Lack of standards hampers meaningful data exchange and use across different information systems. Infrastructure for electricity and connectivity especially in the countryside must be established more urgently to meet over-all development goals specially. Policy and operational gaps identified in this study have to be addressed using peoplecentric perspective and participatory strategies with the urgency to achieve universal health care. Further rigorous research studies need be done to evaluate CHITS' effects on public health program management, and on clinical outcomes.
\end{abstract}

Key Words: Electronic Medical Records; Health Information Systems; CHITS; Universal Health Care, Routine Health Information System

* Major content herein was presented during the Research Forum at the National Institutes of Health, Ermita, Manila on June 14, 2012. Where relevant, data were updated.

Corresponding author: Arturo Ongkeko Jr., RN

National Telehealth Center

National Institutes of Health

University of the Philippines Manila

3rd Floor IT Complex, Philippine General Hospital

Taft Ave., Ermita, Manila 1000 Philippines

Telephone: +6325091003

Email: amongkeko@up.edu.ph

\section{Introduction}

eHealth is the use of information and communications technology (ICT) for health, recognized as an enabling tool to help meet service delivery objectives. This paper describes an electronic medical record system (EMR) for government primary care health centers in the Philippines, more specifically, the Community Health Information and Tracking System (CHITS), whose longevity - through peer and policy adoption - speaks of an eHealth technology built for and by the people.

CHITS was developed by the University of the Philippines-Manila (UP Manila) in 2004 as a research on computer-based information systems. To respond to user needs, CHITS was designed as an EMR for Pasay City health centers, with consideration of 3000 other such facilities having the same needs in 1,493 municipalities and 143 cities nationwide. An EMR is a "computerized medical record created in an organization that delivers care, such as a hospital or clinic, as part of a local stand-alone health information system (HIS) that allows storage, retrieval and modification of records." ${ }^{1}$ The Department of Health (DOH) developed a similar electronic field data reporting system in 2002, improved it and subsequently oriented rural health unit (RHU) workers on its use nationwide. In the last five years, the private sector has taken interest in developing EMR for government health facilities as well.2,3,4,5 To date, five EMR systems, including CHITS, have been implemented in about a third of all government primary care centers in the country.

Current health information systems for primary care in the Philippines

The Field Health Service Information System (FHSIS) is the official recording and reporting system of the Philippine DOH. Conceptualized in 1987, and implemented nationally in 1989, the FHSIS is now on its fourth modification. The FHSIS is a set of information systems on priority government programs intended to monitor health service delivery using key indicators. However, not all programs are included such as those on the control of rabies and noncommunicable diseases. It is a manual, paper-based system where health services provided at the front lines are 
recorded and reported by midwives and nurses at the primary care level health centers (RHU or city local health centers). Data requires aggregation at several levels of the health system - at the health facility, at the City or Provincial Health Office $(\mathrm{CHO} / \mathrm{PHO})$, at the regional offices of the $\mathrm{DOH}$, and at the National Epidemiology Center of the DOH. In 2011, manually recorded health services and manually aggregated data began to be entered and reported electronically to the DOH Regional Offices through the electronic FHISIS (eFHSIS).

Leaders make critical decisions on the health of community and country based on quality information and evidence. The World Health Organization defines a wellfunctioning health information system (HIS) as one that "ensures the production, analysis, dissemination and use of reliable and timely health information by decision-makers at different levels of the health system, both on a regular basis and in emergencies." 6 Health information systems in developing countries are beset with many challenges: paperbased and manual recording and consolidation are prone to human error. ${ }^{7}$ Marcelo describes the Philippine HIS to follow the "all-or-none phenomenon and hierarchical flow of data" - data from all the barangays of a local health center or RHU need to be complete before these get to be submitted to the $\mathrm{CHO}$ or $\mathrm{PHO}$, and so on, until it reaches the DOH central offices. ${ }^{8}$ This delays the submission of higher level reporting units because of missing data from constituent facilities. Health program target-based reporting, while objectivedriven, can be counter-productive especially in a paperbased system where there is more opportunity for manipulation for more socially acceptable reports. Vertical programs, each with its own compulsory logbook and reports, demand that health workers enter the same data repetitively in multiple books, a setting for erroneous reporting of service statistics. For instance, the consult of a pregnant woman with tuberculosis should be reported in at least the daily service logbook, maternal health program target client list (TCL), and the tuberculosis program TCL. While the specific-per-program TCL is intended to support the continuing care for patients with a specific condition and provide each public health program manager with a unified view of patients covered, the vertical system of reporting reinforces a disintegrated perspective of health care. Finally, manually recorded and reported data become "data cemeteries" when paper reports are archived in their health facility; voluminous logbooks and records are daunting to tackle and difficult to process as basis for planning, or even simple research for health facility surveillance needs.

These HIS concerns should be considered amid other health system challenges, on which DOH Secretary Ona in 2010 lamented: "The devolution of health care in 1991 paved the way for the fragmentation of the health care delivery system in the country, from a monolithic health system into several independent health systems." ${ }^{\prime \prime}$ Each municipality, city or province can adopt (and in fact, many have already adopted) electronic HIS without regard for standards and data sharing.

This was the context for CHITS development, over a decade ago. CHITS was a project of the UP College of Medicine implemented in close collaboration with the City Health Office of Pasay, and funded though the Pan Asia ICT Research \& Development Grants. The UP Manila National Telehealth Center (NTHC) has since taken responsibility for its development and implementation beginning 2006. It is an open source, modular and extensible system that integrates existing routine but vertical health information systems of public health programs. A key feature of CHITS is its userfriendly interface, which presents to the health worker a single unified view of the various $\mathrm{DOH}$ program data fields.

\section{eHealth towards Kalusugang Pangkalahatan}

After almost fifteen years of health sector reform, this current Philippine government recognized health information as one of the six strategic instruments of Kalusugang Pangkalahatan (Universal Health Care) to achieve Philippine President Aquino's health agenda. Thus, in 2010, the $\mathrm{DOH}$ articulated its aims to establish a (better national) health information system that shall provide: (1) evidence for policy and program development, and (2) support for immediate and efficient provision of health care and management of province-wide health systems. ${ }^{10}$

CHITS development and implementation was based on the hypothesis that, unlike other ICT systems, people-centric development and deployment of CHITS enable technology adoption among typical government health workers, and allow its scale and sustainability. While antedating the DOH's call, CHITS, as an EMR and the fundamental source of patient information and services received, was proposed and implemented to improve the process of data management that would, in turn, result in better quality and more reliable health information for individual patient care as well as public health management.

\section{Objective}

This case study describes the design, development and implementation of CHITS. It discusses the enabling factors and challenges influencing its adoption, expansion and sustainability as an EMR system in government primary care health facilities.

\section{Methods}

This paper uses the case study approach to explain how a technology innovation in health care has persevered through time and slowly extended its geographic footprint. Data comes from CHITS electronic data and NTHC technical (and field) reports on CHITS implementation, and evaluation research by graduate students from institutions outside of UP Manila. Technical reports include qualitative data extracted 
from interviews and focus group discussions (FGD) among health workers of selected CHITS implementation sites in Pasay City, Navotas City, Quezon City, and in the provinces of Tarlac, Albay, Northern Samar and Sarangani within six months after the CHITS training. Electronic data from CHITS provide counts of services rendered to patients.

Forty-five (45) health facilities - 30 health centers and three lying-in-clinics in the five districts of Quezon City, eight health centers and one lying-in-clinic of Navotas City, and RHUs of Sto. Domino, Albay, Gamay, North Samar and Glan, Sarangani - were subjected to a time motion study to evaluate the average records retrieval time before the implementation of CHITS (conducted from 9am to 11am, in February to April 2012). Records retrieval time is defined as the time that it took for the RHU staff to secure a patient's paper-based Individual Treatment Record from the designated RHU records section; this is clocked when the staff member enters the records section or turns to face the shelf of paper records and ends when the staff member successfully locates the patient's medical file. In the same 45 health facilities, average staff time spent in recording and preparing reports for the FHSIS TCL and Monthly Health Services reports for maternal health program was also evaluated. Data is drawn from a self-administered questionnaire involving front-line health staff available at the 45 health facilities (range of 7-10 nurses and 30-35 midwives per rural or urban health facility). Each listed one's estimated amount of time (in minutes) spent sorting data from services rendered from the Individual Treatment Records, compiling these into the TCL and Monthly Activity Reports for maternal health of the immediate past month. Responses were tabulated to compute for the mean amount of time spent for each TCL or Monthly Activity Report.

On implementation of CHITS, records retrieval time is defined as the time when the RHU staff encodes the patient's surname in the General Consults data field, selected from a list of possible patients with the same surname and the specific patient record is displayed. Staff time spent in recording and preparing reports for the FHSIS TCL and Monthly Activity reports for maternal health program is measured when the RHU staff selects the tab on Reports, encodes the time period for the report, select either the TCL ("Consolidated Report") or Monthly Activity report from the drop down button, then ends when the report is displayed.

Factors that enabled and challenged CHITS implementation are analyzed using HOT-fit framework developed by Yusof et al.; analysis using Rogers Diffusion of Innovation framework (1986) is incorporated therein. ${ }^{11}$ The original CHITS developers also cite Heek's ITPOSMO Model (2003), and recounted to set context. ${ }^{12}$

\section{Scope and limitations}

CHITS status is documented in NTHC's CHITS project technical reports. This case report discusses CHITS development and implementation in 50 facilities that used CHITS version 1 from 2004 to 2012. Except for Pasay City, which is visited and supported since it is the partner community for academic community medicine of UP Manila, NTHC was in touch with the physician-health officer of the 40 other health centers through telephone only within the first six months of implementation. This paper also covered the development and early implementation of CHITS version 2 in 89 health facilities up to May 2012. Evaluation of CHITS done by researchers not connected with the UP Manila are also cited (e.g. Premji, Lacbawan, Versoza, et al.).

\section{Results}

\section{Software Development Process}

The process of CHITS development in 2004 followed the spiral lifecycle model of Clements, with four phases. ${ }^{7}$ The project planning phase involved determining the objectives of the end-users and the functional and technical specifications of the software. CHITS was initially conceptualized as a mobile-based, child health injury tracking system. ${ }^{7}$ Preliminary findings revealed several constraints associated with the original research intent and strategy. Whereas government primary care centers attend to patients with injuries, the patient load in a typical health center consists mainly of pregnant patients and infants seeking wellness consults (prenatal care and immunization, and well child), as well as patients with tuberculosis and children with a range of illnesses. And while the original research was for villagebased community health, volunteers report on injuries occurring in the communities to facilitate care at the RHUs; the typical middle-aged community health volunteer relied on their younger children to use cellphones for their communication needs in the early part of 2004. Thus, the project was appropriately modified, renamed and took the current character of CHITS. It shifted in three ways: from being village-based, intended to support village community volunteers to report injuries through the use of mobile phones, to health facility-based that addressed government health staff's need for improving documentation of major health services rendered to patients through the use of desktop computers. On a daily basis, health workers are service providers. Thus, CHITS had to be an EMR that [1] codifies their patients' clinical conditions and the care the health workers provided; [2] tracks patient health status; and [3] reminds them of services for patients seeking or needing follow-up care. In addition, the Pasay health workers needed a better way to meet their public health responsibility on health data reporting, i.e. CHITS had to address the timeconsuming ritual of afternoon report-making. CHITS was then developed to automatically draw together information from the database and aggregate these into DOH-FHSIS compliant reports. Systems analysis was done side by side with the health workers through immersion of researchers in 
the workplace to understand the "social context, capture an accurate model of organizational and personal realities [as well as to] gain [better] insight into the end-users' needs and requirements". ${ }^{13,14}$ The functional requirements gathered during the planning phase were validated with the health workers through wireframes (system mock-ups or prototypes). The team also determined and discussed the priority heath programs form bulk of services they provide to their patient base: Expanded Program for Immunization, Maternal Care and Tuberculosis programs, as well as the general patient consults. These became the software modules and feature sets; potential risks and alternatives were also considered. Joint rapid development involved software coding, a significant portion of which occurred onsite in the local health center to quickly respond to enduser feedback. The evaluation phase followed immediately after each rapid development cycle for each health module created and final approval from end-users is sought. A new software development cycle commences to meet the required health modules.

\section{Free and open source software}

CHITS runs on free and open source software (FOSS); its second version beginning 2011 uses the Open Medical Records System (OpenMRS, http://openmrs.org) as a platform, which is a collaborative open source project that allows organizations to adopt and modify the code without the need to develop a system from scratch. ${ }^{15}$ It is founded on the principles of openness and sharing of ideas, software and strategies for deployment and use. Thus, even when CHITS software developers move to other projects, the CHITS-OpenMRS software can be studied and modified freely by others.

\section{CHITS deployment and training}

The CHITS training program engages the health workers throughout a span of at least six months. Its key elements are re-education on ethics and data privacy in the digital age. An analysis of the current health information system allows health workers to appreciate and to articulate for themselves characteristics of quality health information. These are foundational concepts to anchor hands-on training on basic computer skills, navigating the use of various health services modules to document patient care and generate the $\mathrm{DOH}$ reports. The andragogy process includes games and structured learning exercises, as well as post-training support.

\section{Use of CHITS}

A total of 124,389 patient consults have been recorded in CHITS for the period of 8 years of use by the pioneer urban Lagrosa Health Center. This is about 65 patients seeking care daily in a health facility that serves a population of about 32,000. In May 2012, the new version of CHITS was installed in a total of 89 government health facilities, with about 840 health workers trained. Among these is rural Sto. Domingo, Albay wherein 1,622 patient records have been created in the first three months of CHITS. The town also serves about 30,000 people, or about 27 patients served daily in the RHU in the town center.

\section{The immediate returns: operational efficiencies}

In spite of the increased time demanded by CHITS during initial patient registration, health workers expressed that CHITS, in fact, improved health center efficiency to allow them to perform their health promotive and preventive functions in the community better. This is demonstrated in the time saved doing manual tasks. The time to retrieve patient medical records and the time to prepare the FHSIS monthly reports and TCL have since been reduced to less than five seconds when CHITS was used, as documented in the newest implementation sites. Figure 1 depicts the pre-CHITS time

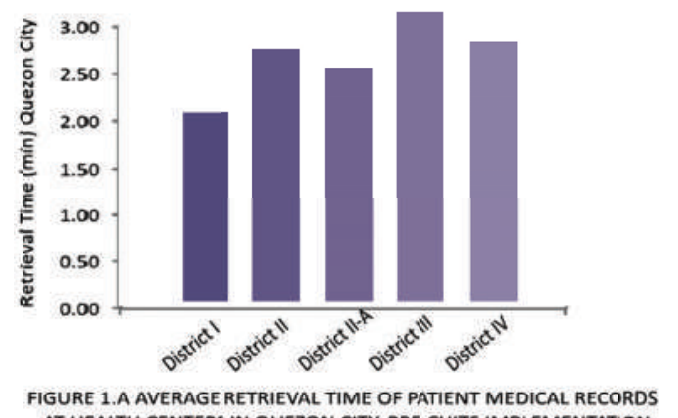
AT HEALTH CENTERS IN QUEZON CITY, PRE-CHITS IMPLEMENTATION

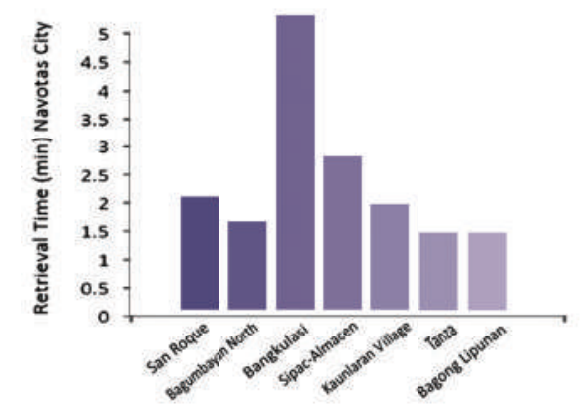

FIGURE 1.B AVERAGERETRIEVAL TIME OF PATIENT MEDICAL RECORDS AT HEALTH CENTERS IN NAVOTAS CITY, PRE-CHITS IMPLEMENTATION

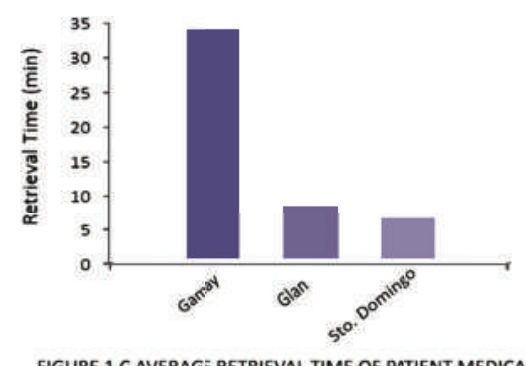

FIGURE 1.C AVERAG: RETRIEVAL TIME OF PATIENT MEDICAL RECORDS AT HEALTH CENTERS INSELECTED GIDA AREAS, PRE-CHITS IMPLEMENTATION

Figure 1. Average retrieval time of patient medical records at health centers in selected study sites, pre-CHITS implementation. 
needed to retrieve paper-based medical records in 45 health facilities previously described. For Quezon City, it was observed that it ranges from an average of 1.94 to 2.92 minutes in its five districts for 33 out of its 73 health centers. For Navotas City, time ranges from 1.94 to 4.14 minutes; for GIDA municipalities, Gamay was 30.21 minutes, Glan was 4.72 minutes and Santo Domingo was 2.72 minutes.

Figures 2 to 3 depict pre-CHITS time needed to prepare the FHSIS TCL and monthly reports in the same areas, respectively, which ranges from 20 minutes to 3.84 hours (230.4 minutes) for TCL, and 1.0 to 13.8 hours for monthly reports in the sites observed. Since CHITS aggregates the summary reports, the time to generate them has been reduced to five seconds to about a minute, depending on the skill of the health worker, when CHITS was implemented. ${ }^{16}$
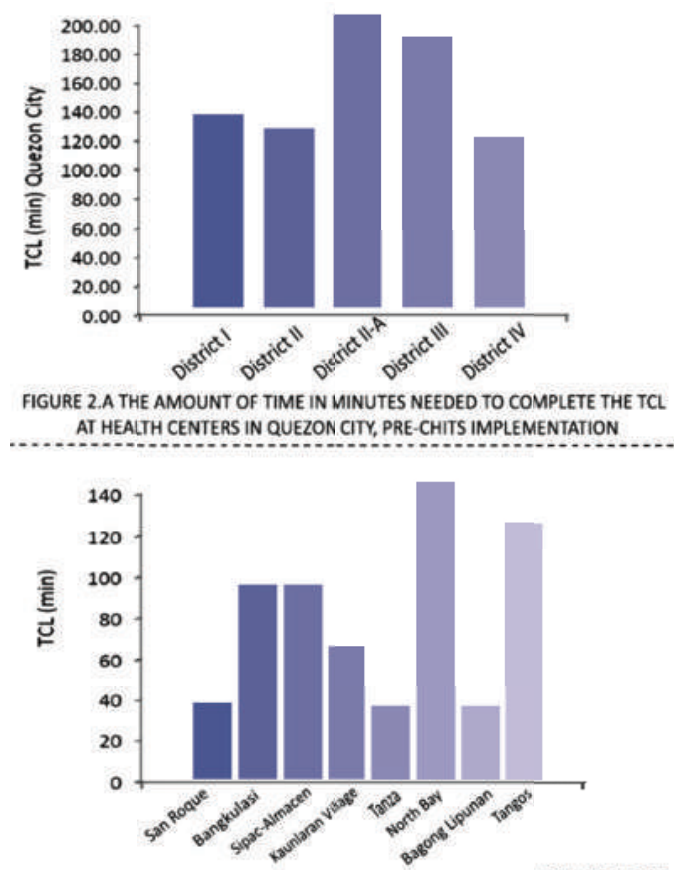

FIGURE 2.8 THE AMOUNT OF TIME IN MINUTES NEEDED TO COMPLETE THE TCL. AT HEALTH CENTERS IN NAVOTAS CITY, PRE-CHITS IMPLEMENTATION

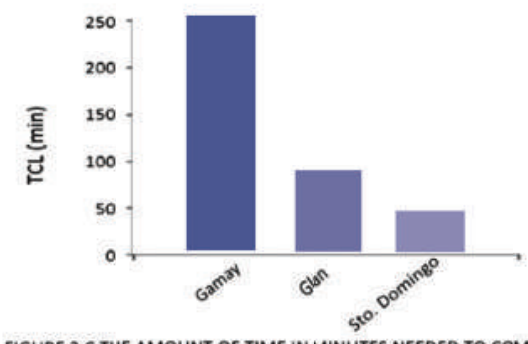

FIGURE 2.C THE AMOUNT OF TIME IN MINUTES NEEDED TO COMPLETE THE TCL AT HEALTH CENTERS IN SELECTED GDA SITES, PRE-CHITS IMPLEMENTATION

Figure 2. The amount of time in minutes needed to complete the TCL at health centers in selected study sites, pre-CHITS implementation.
With the appointment system built in CHITS, health workers can now easily track defaulters without going through voluminous pages of TCL. ${ }^{17}$ Similarly, the appointment system enables the RHU or health center physician to project the daily patient load, and thus, distribute the health staff to different service stations appropriately.

\section{Benefits sustain continuous use of CHITS}

When asked why they still use CHITS, nurses and midwives from the first two pilot CHITS implementation sites in Pasay City expressed appreciation for what has become eight years of routine CHITS use. Views of health workers reflect its good integration in their clinical workflow, a habit already developed, as reflected in these statements:
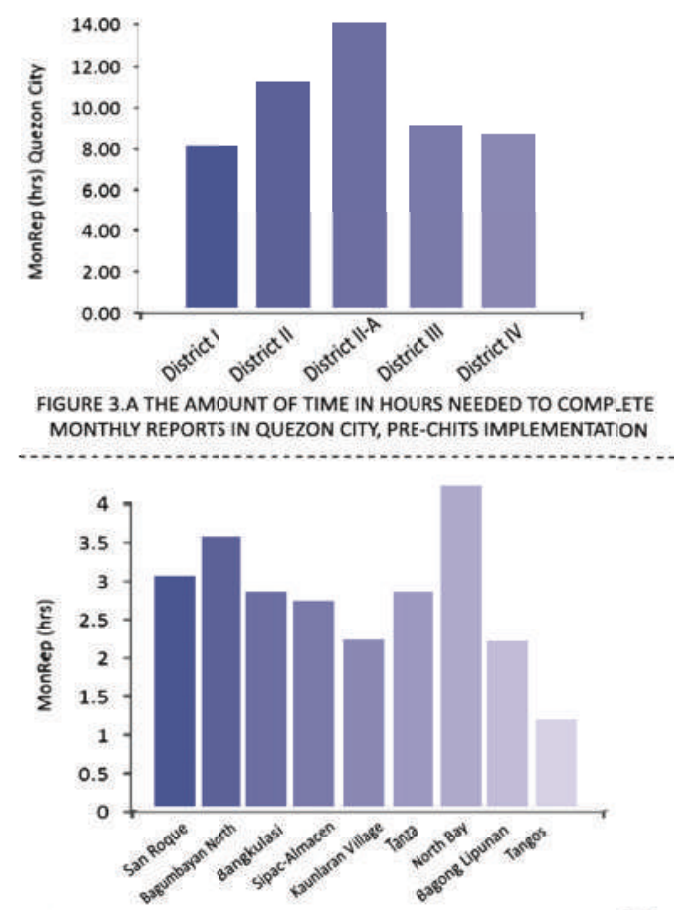

FIGURE 3.B THE AMOUNT OF TIME IN HOURS NEEDED TO COMP.ETE MONTHLY REPORTS IN NAVOTAS CITY, PRE-CHITS IMPLEMENTATION

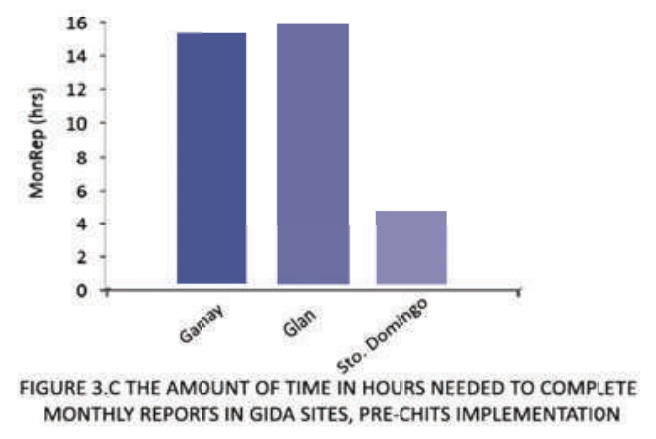

Figure 3. The amount of time in hours needed to complete monthly reports in selected study sites, pre-CHITS implementation. 
"CHITS is fun. During power interruptions, the health staff members are hot-headed when we don't have CHITS and have to use paper-records. In the health center, CHITS is the life of the staff; life is incomplete without CHITS)..."

"We're slow at first but with continuous use we can accomplish more work. I will no longer have calloused finger tips...I don't want to go back to paper anymore" (54 years old, Nurse). ${ }^{17}$

Other health workers in RHUs of varying stages of CHITS implementation share about improved health information management:

"We no longer get confused in searching for missing records! We can already retrieve it in a single click (Midwife, Quezon City)."

"Despite my age, I have learned to use the computer. I am happy. Aside from new learning, I can get to generate my reports immediately."(Nurse, Navotas City).

"A heavy weight was taken on my chest! I can now print the reports that I need. Really big help." (Midwife, Navotas).

These also reflect benefits accrued to the health workers in acquiring a new skill, and easing much of their workload.

There is an improved health care environment:

"I am very happy. CHITS is a nice/good improvement for us. (Physician, Pasay City, began using CHITS in 2010).

"You can never be wrong with CHITS; it is foolproof and very user-friendly" (Physician, Paniqui, Tarlac, began using CHITS in 2010).

"My table is no longer cluttered because of paper piles. And because I am used to typing, I can now accomplish my work much faster" (Nurse, Navotas). ${ }^{18}$

Premji in 2012 reports: "despite an initial fear of technology, health center workers were empowered by CHITS and found reporting to be easier and more efficient." They also had a growing appreciation for the value of data collection and better understood the value of collecting accurate and verifiable population health information and its role in effective decision-making. Health workers also report "more time for patient care and community work."19

Other benefits are improved data security, savings on paper, and better records management. Although paperbased patient records are stored in shelves in distinct areas of the RHUs, CHITS data is regarded by the health workers to be more secure in that only authorized health care staff are able to access the information by logging into CHITS with their own username and password. ${ }^{20}$ Pasay City Health Centers have gone virtually-paperless, thus, CHITS is perceived to be "environment-friendly". (This was never quantified, however; the increased electricity use due to CHITS and the manufacturing and disposal of ICTs have not been accounted for in terms of its environmental costs.)
Lacbawan in her study of Pasay City's patient perceptions on CHITS, reports that there is "overall satisfaction with the technology, the CHITS did not compromise time and quality interaction with the physician $(p=0.005)$, and (it) was not confusing $(p<0.014) .{ }^{21}$ When respondents were asked when does the CHITS become useful, patients shared about the "efficient recording of patients", "the faster transfer of health information or statistics to the Philippines Department of Health", "shortens overall clinic time, because the questions of the doctors are minimized since he already knows the medication the patient is taking..." A 21-yearold female patient who was asked for follow up care at San Isidro health center cited how difficult it is to go from health center to a hospital because "CHITS is not accessible at hospitals." A new 27-year-old female patient at Villamor health center asked if CHITS was available in provincial hospitals. These two latter statements reflect a positive desire to have separate health facilities interconnected through CHITS.

\section{Building on what we have: CHITS expansion through the years}

From two original health facilities, CHITS gradually spread to 50 health centers by the end of 2010, mainly through colleagues from other RHUs or City Health Offices who were attracted with the initial success of CHITS in Pasay City. From March to May 2012, the new version of CHITS was installed in 89 health facilities in Navotas and Quezon City, as well as three rural municipalities. Figure 4 depicts milestones and Table 2 lists the contribution of government and non-government partners of the UP Manila - in CHITS expansion in terms of additional health program modules and features, as well as geographic spread.

\section{International and national recognition, and research done on CHITS}

Since its conception in 2004, CHITS won several awards and received citations in both national and international arena (Table 1). CHITS is also well-studied by researchers outside of the UP Manila, contributing to its growth and rigor (Box 1).

\section{Information use to improve service delivery}

Beyond automating patient records and submission of $\mathrm{DOH}$ reports, only one anecdote has been recorded about how CHITS data was actually used for local health program management. (This was in Pasay City and the 2009 campaign against teenage pregnancy in the locale. The adolescent reproductive health campaign was based on CHITS-culled data from a succession of years showing increasing numbers of pregnant teens seeking maternal care.) There has to be more of these case stories on CHITS use for public health program decision-making. 


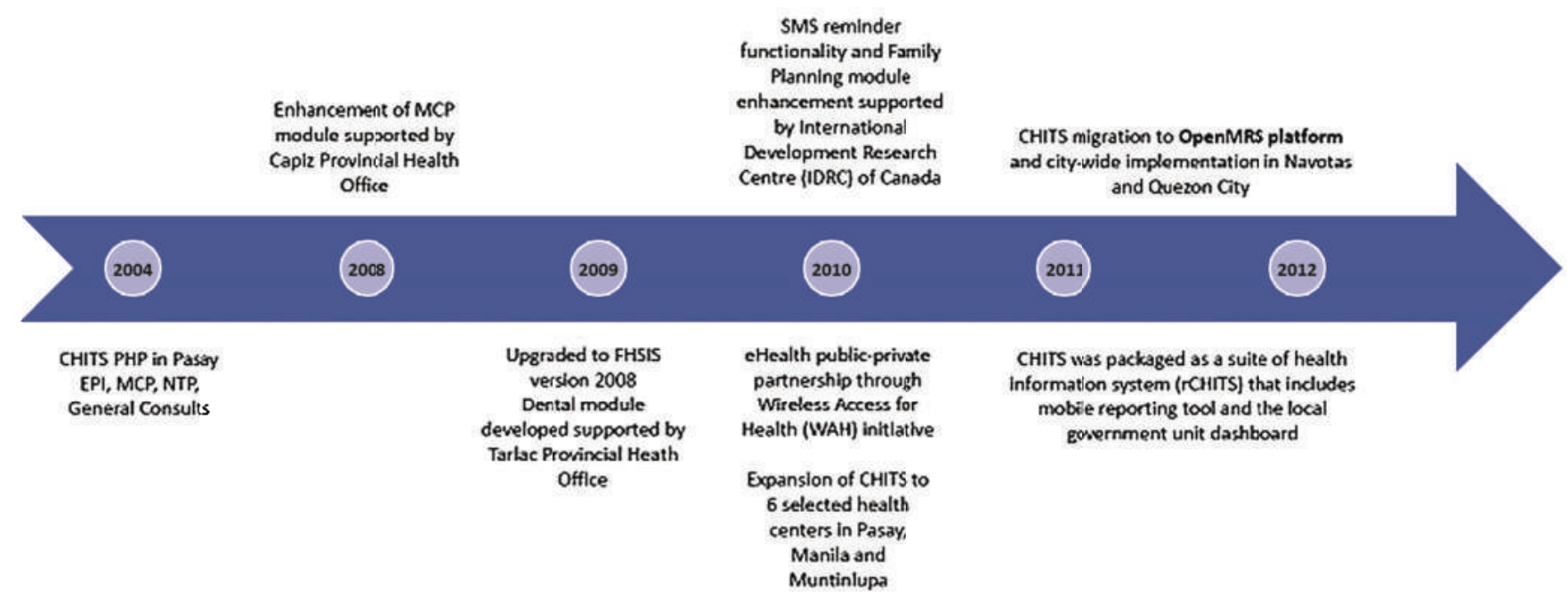

Figure 4. Building on what we have: community investments in CHITS development through the years.

Table 1. International and national awards and citations

\begin{tabular}{lcl}
\hline \multicolumn{1}{c}{ Award } & Year & \multicolumn{1}{c}{ Description } \\
\hline $2^{\text {nd }}$ Runner-up, 2014 Jesse & 2014 & $\begin{array}{l}\text { The CHITS (Community Health Information and Tracking System) citywide implementation in Quezon City } \\
\text { won 2 }\end{array}$ \\
$\begin{array}{l}\text { Robredo } \text { Awards for } \\
\text { Excellence in ICT (Award for }\end{array}$ & & $\begin{array}{l}\text { Technologies (ICT) for good governance to efficiently and effectively deliver public services to stakeholders. } \\
\text { CHITS) }\end{array}$
\end{tabular}

\author{
This is in the "Best in eGov Customer Empowerment (G2C)" category of the $3^{\text {rd }}$ eGov Awards for Local \\ Government Unit (LGU) in 2014, conferred by the Department of Interior and Local Government (DILG) and the \\ National ICT Confederation of the Philippines
}

Best Market Innovation Award (CHITS)

Best Market Innovation Award (CHITS)

CHITS presented in the renowned Prince Mahidol Awards Conference 2010 Finalist for Stockholm Challenge (Award for CHITS)

ICT Best Practices for eGovernment Award (CHITS) Compendium of Best Practices in Local Health Systems (CHITS) One of the Best Programs of the University of the Philippines Manila (CHITS)
CHITS is the country's first electronic medical record system developed by and for government health facilities (see NTHC milestones). In 2011, the CHITS was implemented in all 73 primary care government facilities in the largest and most populous city in the country, and funded through the Quezon City Local Government.

Novemb CHITS won the "Best Health Market Innovation Award" in Galing-Likha Kalusugan Awards. Galing-Likha er 2011 recognizes innovative health programs that have changed how health care transactions are delivered in the market place. This was conferred by the Center for Health Market Innovations (CHMI) and the Philippine Institute for Development Studies (PIDS, CHMI's Philippine partner). It receives support from the Bill \& Melinda Gates Foundation, the Rockefeller Foundation, and UKaid.

CHITS topped 117 other health programs in health care service delivery, financing, facilitation, regulation, and promotion that have creatively address problems that plague health care in the Philippines.

Novemb CHITS, as part of the Tarlac Province's Wireless Access for Health (WAH) Project, in Galing-Likha Kalusugan

er 2011 Awards, conferred by the Center for Health Market Innovations and the Philippine Institute for Development Studies. WAH also models public-private sector partnerships in health innovation.

${ }^{*}$ CHITS was recognized as Best Market Innovation twice in this 2011 Galing-Likha Kalusugan Awards January CHITS was featured by IDRC in the Prince Mahidol Awards Conference in January 28 to 31, 2010 in Bangkok,

2010 Thailand. It was a GLOBAL HEALTH INFORMATION FORUM which launched the $2010 \mathrm{a}$ 'Call to Action' on Health Information Systems.

2006 CHITS was among the finalists chosen from among 1160 entrants to the Stockholm Challenge by the City of Stockholm, Sweden. The award is given to projects that utilize ICT in improving lives of disadvantaged communities. The Award originated as the Global Bangemann Challenge.

2006 CHITS was among the awardees of the ICT Best Practices for e-Government at Asia Pacific Economic Cooperation Digital Opportunities Center (ADOC) Awards, in Taipei, Taiwan.

2006 CHITS was included in the Compendium of Best Practices in Local Health Systems, Department of HealthNational Capital Region.

2005 CHITS was among the "Best Programs of UP Manila", presented by UPM Chancellor Marita Reyes to Dr. Emerlinda Roman on her inauguration as the $19^{\text {th }}$ President of the UP System. 


\section{Problems encountered with CHITS}

By the end of 2010 or six years since CHITS was first implemented, the original CHITS version was installed in 50 health facilities as far north in Batanes province and south of the Philippine archipelago in Zamboanga peninsula. By mid2012 , however, only 30 of these RHUs or $60 \%$ of those who tested the CHITS remain using CHITS. Physicians from towns or facilities that ceased using CHITS cite mainly hardware breakdown problems - many were due to electrical surges in the rural locale, coupled with the lack of local ICT support, and loss of (resigned or transferred) RHU health personnel trained on CHITS. Health workers have no recent recall of patient records lost when they shifted to CHITS. But they do report concern on duplication of family folders when faced with patients who use various surnames, or are not consistent with their reported civil status or home addresses. ${ }^{18}$

A variety of hardware, router and CHITS software problems were reported by Pasay City health staff and resolved through technical support by the NTHC throughout these years. The latter is mostly due to improper shut down of computers during occasional brown-outs or

\section{Box 1. CHITS in Research and Publications}

\section{Published Works}

1. Herman D. Tolentino, MD, Alvin B. Marcelo, MD, Inocencio D.C. Maramba, MD, MSc, Portia F. Marcelo, MD, MPH, Malou San Juan, MD, Ma. Irene Sy, MD, MPHC, Armand Lee, MD, Marvin Yoingco, MS (cand.), Ariel Betan, MA, MS (cand.). 2006. Community-Based Injury Surveillance Tracking System. PAN ASIA ICT R\&D Grants Programme. Pp. 32-5.

2. Herman Tolentino MD, Alvin Marcelo MD, Portia Marcelo MD MPH, Inocencio Maramba MD MSc, 2005. Linking Primary Care Information Systems and Public Health Vertical Programs in the Philippines: An Open-source Experience. AMIA 2005 Symposium Proceedings. pp. 311-5.

3. Tolentino H, Marcelo A, Marcelo P, Maramba I. 2005. Linking primary care information systems and public health information networks: lessons from the Philiippines. Studies in Health Technology and Informatics. V116:955-60.

4. Flores-Zuniga AE, Win KT, Susilo W. 2010. Functionalities of free and open electronic health records systems. International journal of technology assesment in health care. V26 n4: 382-9.

5. Marcelo A and Fernandez-Marcelo P. The Community Health Information and Tracking System: Quality Care through Information Management, pp. 154-70 in Fernandez-Marcelo P. ed., 2010. Partnership Matters: Lessons from a Decade of Collaboration between the UP College of Medicine and Pasay City. University of the Philippines. Manila, Philippines

6. Marcelo AB. Health information systems: a survey of frameworks for developing countries. Yearb Med Inform. 2010:25-9.

7. Sainz de Abajo, Beatriz and Agustín Llamas Ballestero. "Overview of the Most Important Open Source Software: Analysis of the Benefits of OpenMRS, OpenEMR, and VistA." Telemedicine and E-Health Services, Policies, and Applications: Advancements and Developments. IGI Global, 2012. 315-46. Web. 10 Jun. 2012. doi:10.4018/978-1-4666-0888-7.ch012

"Community Health Information Tracking System (CHITS) is prestigious open source software for medical records management designed for local health centers in the Philippines."

\section{Unpublished Research}

Bermejo RA and MAC Catangui. 2012. CHITS-OpenMRS Pre-Implementation Study: Improving Operational Efficiency in Health Information Management in Government Primary Care Clinics

\section{PhilHealth Research Study Group, National Institutes of Health, University of the Philippines in Manila (2007)}

\section{Joselito M. Montalban, Faith Victory A. Mejor. montculapius@gmail.com}

Evaluation of a Primary Care Computerized Information System as a Monitoring Tool for Utilization of the Outpatient Benefits of the Philippine National Health Insurance Program in Selected Health Centers in a Metropolitan Area [presented to the NEDA / National Economic Development Authority (Project Monitoring Staff, and Social Development Staff), and endorsed by PhilHealth for adoption nationwide (2010)]

\section{Thesis of Graduate and Undergraduate Students}

1. Shainur Premji, MSc, with Scott RE, Currie G. (June 2010) shainur@gmail.com

The Development of a Framework to Evaluate the Organisational and Policy Impacts of CHITS in the Philippines. Global e-Health Research and Training Program. University of Calgary, Calgary, Canada.

2. Ley Nadine Lacbawan, MPH. (May 2011) llacbawan@gmail.com

Patient Perceptions of EHR and CHITS technology on delivery of care in Pasay City, Metro Manila, Philippines. Department of Global Health School of Public Health and Health Services, The George Washington University, Washington, D.C. USA.

3. Aliyah Lou Arriola Evangelista, BA (April 2011) alaevangelista@gmail.com

Capacity-Building and Teachnology Diffusion Strategies Used in the CHITS End-User Training to Empower Community-Based Health Workers. College of Development Communications, University of the Philippines Los BaÑos

4. Versoza, Jonas Ian R., Verzosa, Meliza Mae B., Vidal, Louise Angelique A., Vidallon, Beatrice P., Villamor, Patrick Joseph D., Villanueva, Diana Marie M., BSN (2011) beavidallon@yahoo.com

An Evaluation of CHITS Users' Behaviours in Selected Health Centers in Pasay City, Metro Manila. College of Nursing, University of Santo Tomas

5. Asinas, J., et al. BA. (2013). Health CHITS: Promoting Productivity through An Innovative Health Information Tracking System. Ateneo de Manila University.

6. Domingo LC. MBA-Health (2015). Teknolohiya sa Likod ng Kalusugan: A Sequential Mixed Method Study on the Navotas Health Workers' Adoption of an Electronic Medical Records System. Ateneo Graduate School of Business, Ateneo de Manila University. 
when new health workers, not formally trained on CHITS, misses the sequence of shutting down the CHITS program then the computer.

Likewise, when CHITS modules were updated in 2008 and 2010, the pioneer health facilities with high patient loads complained of slowed down processes. These would be resolved by the software developers, although concern about the technical sturdiness of CHITS is already being discussed. Lacbawan also documented Pasay City patient views when asked about when the CHITS EMR was not useful to them: "(It is a) problem if system or computer sometimes doesn't work"... "problem if health workers are still not used to the system; sometimes finding my record is slower." 21

Table 2. Community contribution to CHITS development and geographic expansion

\begin{tabular}{|c|c|c|}
\hline & Partners & Health Facilities \\
\hline $\begin{array}{l}\text { Original } \\
\text { research }\end{array}$ & $\begin{array}{l}\text { Pan Asia ICT R\&D Program and UP Manila } \\
\text { College of Medicine - Medical Informatics Unit } \\
\text { with Pasay City Health Office }\end{array}$ & Lagrosa and Malibay Health Centers in Pasay City \\
\hline \multicolumn{3}{|c|}{ Partners in Geographic Expansion } \\
\hline & Partners & Health Facilities \\
\hline \multirow[t]{14}{*}{ Government } & $\begin{array}{l}\text { Batanes Provincial Government and Provincial } \\
\text { Health Office }\end{array}$ & Batanes Provincial Health Office Clinic \\
\hline & Municipal government and RHUs & Uyugan, Batanes \\
\hline & & Orion, Bataan \\
\hline & & Alfonso, Cavite \\
\hline & & Mendez, Cavite \\
\hline & & Pagsanjan, Laguna \\
\hline & & Perez, Quezon \\
\hline & & Quezon, Quezon \\
\hline & & Alabat, Quezon \\
\hline & & Real, Quezon \\
\hline & & Loreto, Dinagat Island \\
\hline & Marikina City Government & Marikina Heights, Sto.Nino and Taniong Health Centers \\
\hline & Pasay City Government and City Health Office & 3 health centers \\
\hline & $\begin{array}{l}\text { DOH - National Capital Region and WHO - } \\
\text { Philippines }\end{array}$ & 6 health centers in Pasay, Manila and Muntinlupa Cities \\
\hline \multirow{5}{*}{$\begin{array}{l}\text { Non- } \\
\text { government }\end{array}$} & Gawad Kalinga & GK Clinic, Tatalon, QC \\
\hline & Child Hope Asia-Pacific & CHAP Mobile Health Van \\
\hline & $\begin{array}{l}\text { Smart Communications and Pasay City Health } \\
\text { Office }\end{array}$ & 3 Health Centers \\
\hline & Ateneo de Zamboanga School of Medicine and & 3 health centers in Zamboanga City (Labuan, Limpapa, Patalon), 3 RHUs in Zamboanga \\
\hline & Municipal government and RHUs & Sibugay (Silay, Diplahan, Alicia) \\
\hline \multicolumn{3}{|r|}{ Partners in Research } \\
\hline \multicolumn{3}{|c|}{ (expanding CHITS features and training program, \& geographic scope of implementation) } \\
\hline & Partner & Additional Features \\
\hline \multirow[t]{13}{*}{ Government } & $\begin{array}{l}\text { Capiz Provincial Government and Provincial } \\
\text { Health Office (2008) }\end{array}$ & Updated MNCHN module; implementation in six municipalities \\
\hline & $\begin{array}{l}\text { Tarlac Provincial Government and Provincial } \\
\text { Health Office (2009-2011) }\end{array}$ & $\begin{array}{l}\text { Wireless Access for Health Project, where CHITS was UP Manila's contribution to this PPP for } \\
\text { health governance project }\end{array}$ \\
\hline & & $\begin{array}{l}\text { Updated MNCHN, dental health modules, upgraded to FHSIS } 2008 \text { version, implementation } \\
\text { in \# municipalities }\end{array}$ \\
\hline & Navotas City Government and City Health & mCHITS - using Blackberry phones; maternal and child health modules that synchronizes data \\
\hline & Office (2011 - present) & (and vice versa) with facility-based CHITS; implementation in 8 health facilities \\
\hline & & One database for Navotas City, linking 8 health centers and lying in clinic \\
\hline & & Link with Navotas Cty General Hospital \\
\hline & & $\begin{array}{l}\text { Updated to FHSIS 2012, PhilHealth, TB and NCD modules } \\
\text { module on LGU IT support }\end{array}$ \\
\hline & Quezon City Government and City Health & Shift to OpenMRS \\
\hline & Office (2011 - present) & 18 health program modules; implemented in 73 health facilities \\
\hline & Department of Science and Technology (2012- & RxBox: Integration of Medical Devices in the National Telehealth Service Program \\
\hline & present) & Exchange of clinical data with RxBox telemedicine device, telereferral / teleconsultation (the \\
\hline & & $\begin{array}{l}\text { National Telehealth Service Program) pulling data from CHITS; implementation in } 143 \text { health } \\
\text { facilities in all } 17 \text { regions, plan for implementation to } 1000 \text { other municipalities in } 2016-2017\end{array}$ \\
\hline \multirow{7}{*}{$\begin{array}{l}\text { Non- } \\
\text { government }\end{array}$} & IDRC-Canada (2010) & CHITS with SMS Reminder for maternal care and enhancement of the family planning module \\
\hline & WHO - Philippines and Navotas City Health & Modeling of a citywide health information system in JPMNH* Cities \\
\hline & Office (2011-2013) & MCH modules, Laboratory and drug supply / commodities inventory modules \\
\hline & & Data demand and use \\
\hline & & LGU Dashboard prototype \\
\hline & UNICEF and local governments of 10 & rCHITS Real Time Monitoring of Key MCH Indicators in GIDA through CHITS \\
\hline & $\begin{array}{l}\text { municipalities and RHUs, Quezon City with } \\
\text { the City Health Office ( } 2011 \text { - present) }\end{array}$ & $\begin{array}{l}\text { mReports (software modules on } \mathrm{MCH} \text { - using Android phones/ tablets) - synchronizes data } \\
\text { (and vice versa) through with facility-based CHITS; LGU Dashboard, MInTS, BIRTS }\end{array}$ \\
\hline
\end{tabular}




\section{Discussion}

Thomas and Jone, in the evaluation of 250 IT (information technology) projects from 1995 to 2004, found that only $10 \%$ (or 25) of these were successful: were developed on time, within budget, and acceptable to good design standards. ${ }^{22}$ Seventy percent $(70 \%)$ or 125 projects are considered failure: delayed beyond $35 \%$ of their timelines, budget overrun by at least 35\%, and with design flaws after delivery. This is similar to the 2006 CHAOS Report by The Standish Group which found that only 35\% of IT projects were completed on time, on budget, and met user requirements; $65 \%$ fail.

The American Medical Informatics Association (AMIA) defined successful Health IT applications with the following qualities: "simply getting the application or system turned on, getting people to use it, and getting at least grudging acceptance. There is a caveat that, that grudging acceptance can turn to non-acceptance." 23 By this AMIA definition, CHITS is an unqualified success. Its awards, expansion and adoption by over 50 RHUs nationwide, even without a national policy to back up its use, are proof of diffusion of an innovation that works.

\section{Enablers to CHITS adoption}

The spiral model of software development adopted by CHITS offered solutions to many of IT systems development challenges. The modular approach allowed the developers to quickly redefine what needs to be developed based on the users' feedback. Incremental introduction of change has been an effective strategy to gain insights into the needs and requirements of the health center facilities. This process enabled a more accurate model of existing organizational and personal realities and pain points that serve as the leverage for technology adoption. ${ }^{7}$ This was opted for, deemed much better than waiting three to six months or longer when one uses the waterfall methodology, a classic approach to development that is linear and sequential and does not allow much reflection or revision. Once the application is in the testing age, it is very difficult to go back and make some changes.

Tolentino et al., developers of CHITS, described its early success because of deliberate regard for perspectives of stakeholders of technology projects, across seven dimensions described by Richard Heeks' ITPOSMO Model (2003): Information, technology, process, objectives and values, staffing and skills, management and structure, and other perspectives (Box 2). $7,12,24$

Yusof et al. proposed analysis of health information systems with considerations for human, organization and technology-fit (HOT-fit). ${ }^{11}$ The authors purport that human factors and the organizational context wherein the technology is introduced should be carefully taken into account in order to ensure that the innovation is smoothly integrated (fits) into the behaviour and workflow of target
Box 2. Tolentino et al. (2006), developers of CHITS, described its early "success" using Richard Heeks' 2003 ITPOSMO Model

\begin{abstract}
"Information perspective - CHITS was built to satisfy the information needs of the local government health sector, and specifically address the everyday clinical reporting and the FHSIS reporting needs. Its people-centric approach to software development and implementations, enabling the system to be grow to respond to local and national DOH information needs. Technology - The system was built using FOSS, thus, allowing ownership by the local government of the software application for modifications of the code without restrictions. Process - The system was built using an iterative and spiral model for software applications, modeling subsequent implementations to follow this standard development processes. CHITS can and should undergo refinements necessary, without disregarding what was developed in earlier stages. This allows CHITS to mature while still maintaining consistency with previous installations. Objectives and values perspective - the system was built using a joint application development approach, i.e. the developer was in close proximity with the end-user, thereby allowing changes and refinements on software done at the soonest possible time. It also promoted a sense of ownership for the end-users. The unity in goals and values created an inclusive setting that made users appreciate their participation in the software development process. Staffing and skills - CHITS equally invested in software development as it did in capacity building of the staff who would use the application. It does not only promote the use of information systems, but also fosters a culture of information that makes the end-users appreciate more the value of the data (they are collecting and entering into CHITS) in the broader campaign for a more responsive national HIS. Management and structures perspective - The system is introduced to the health centers and integrated into their existing workflow structure, thereby minimizing switching costs and additional human resource requirements for encoders (which, was resorted to by other initiatives in computerization). Other perspectives - The system, being nonproprietary and non-profit, enables $4^{\text {th }}, 5^{\text {th }}$, and $6^{\text {th }}$ class municipalities to avail of CHITS." 8,24
\end{abstract}

users and institutions. Examples of human factors are level of expertise, champions for the innovation and consideration for habits and workflow patterns. Examples of organizational challenges include health facility culture of innovation (or resistance to change), investments and policies in IT.

Human Factors. CHITS adoption by RHU workers can be attributed to predisposing, enabling and reinforcing factors. Predisposition is "a tendency to a condition." 25 To enable means "to make possible, equip, give ability to" and to reinforce a behavior means "to strengthen with a reward."26 Predisposing factors among RHU workers to use CHITS are their knowledge (of ICTs and value of electronic health records or EHRs in the broader national HIS context), attitude and personal belief (of benefits of ICTs in eHealth and a working HIS). Versoza et al. found a significant relationship between skills and (positive) attitudes of users of CHITS ( $p$ value 0.014). ${ }^{27}$ Basic ICT knowledge of RHU physicians and exposure to CHITS of UP College of Medicine alumni who became public health physicians influenced early adoption in Pasay, Batanes, Quezon and Zamboanga. In general, eight in ten health workers were not computer users prior to 
introduction of CHITS and were truly apprehensive of the system. Yet because of participatory learning methodologies and a staged or modular education style, many have overcome this fear, and later expressed pride in being part of the early adopters of a "high-tech" system in the public health setting. Further, Tolentino asserts that the same mode of training allowed the health workers to view their critical role in the larger fabric of the Philippine health information system: "understanding that facility-level data formed the building blocks of higher levels of analysis (provincial, regional, national). ${ }^{7}$ CHITS was designed to ensure data quality at the collection layer, making possible the transmission of high quality raw data to decision makers at the city or provincial health offices and the National Epidemiology Center." The joint rapid development that occurred, largely onsite and with developers practically beside the health workers, "provided ownership of the (software) application among the staff themselves, thus, strengthening their stake in the project."7 Pasay CHITS pioneers would say, "We invested a lot in CHITS" - their contributions to CHITS software development, modeling its maintenance and upkeep as well as its expansion to other health facilities through peer-to-peer coaching using local resources. CHITS use is reinforced by the reward of learning a new and even futuristic skill. It empowers and builds the selfesteem of health workers; the CHITS experiences affirm that no matter the age, people can be IT-enabled. Another form of affirmation especially for the CHITS pioneers is engaging them to be trainers themselves; they are the natural trainers as CHITS expanded in scope. CHITS adoption is further encouraged by the international and local awards and recognition it received. It is strengthened as well by the growing community of CHITS users.

Organizational Factors. The developers of CHITS assert its relevance to the end-users and the organization they belong: it is "a computer-based information system that served, primarily the needs of the health facility and secondarily, of the national public health system. The conceptualization and design of CHITS evolved from the health workers' needs."7 Everett Rogers identifies qualities that determine the success of an innovation, and is applied to CHITS. ${ }^{28}$ As an innovation, it is perceived to be compatible with their roles, that is, it is consistent with and addresses the needs of potential adopters, i.e. RHU health workers in search an automated solution to minimize reporting and writing tasks. It provides easily observable results such as shorter patient record search time, instantaneous end-of-the day reports for each health service program, sorting of reports by date or period, by sex or age of patients, by barangay etc. as needed. The CHITS system automates processes essentially common to all government primary care facilities nationwide; diffusion of the innovation CHITS - becomes easier in such a homophilous group of health workers.
Successful implementation of CHITS is attributed to the identification and engagement of champion users from the outset. In CHITS, typically, the municipal or city health officers seek the UP Manila as their support are crucial in setting the strategic directions and roles of his/her staff in achieving the maximum benefits of CHITS in their facility. Engagement starts during the needs assessment and social preparation phase, strengthened during the facility administrator's training and ends with a week of dedicated coaching or handholding. In the CHITS experience, in addition to the physicians, nurses and even computerproficient midwives have become champions that sustained its use.

Another critical enabler for adoption and sustainability is policy. The $\mathrm{CHO}$ sets policy and instructs physicians-incharge to transition from paper-based recording to use EMR. The mayor initiates adoption by proposing to the city or municipal council a local government resolution on CHITS, as what happened with Quezon City, Navotas City and Loreto, Dinagat Islands, Mayorga, Leyte and Llanera, Nueva Ecija.

A major enabling factor is financial resource; ICTs are expensive with hardware but the social interventions ensure adoption into clinical workflows. Initial funding from research and development partners such as Pan-Asia ICT R\&D Grant Program in Pasay, Capiz Province, then Qualcom Incorporated and USAID-RTI in Tarlac Province facilitated the launch of CHITS in their respective communities. Once the local chief executives saw the benefits of the innovation, additional resources were allocated to expand and sustain CHITS. Local health leaders and their local governments, non-government development partners, a national government agency enabled the UP Manila to innovate and expand CHITS features and geographic scope further (Table 2).

Local governments eventually began to recognize the potential benefits of CHITS in terms of securing more efficiently revenues. The National Health Insurance Program (or PhilHealth) is a pillar of health sector reform; the Aquino Health Agenda aims for universal coverage and financial risk protection. CHITS is able to monitor PhilHealth enrollment and utilization of RHU services by Philhealth members. In 2006, Montalban and Mejor report “...in light of the demonstrated efficiency and adaptability of CHITS as an information management system for health center operations, it is recommended that it be used in a similar capacity as a monitoring tool for the utilization of PhilHealth outpatient benefits (OPB). ${ }^{19,29}$ In OPB Form 1, 67.7\% of data requirements are found in CHITS and in OPB Form 2, 58.8\%. When the Navotas City Health Office entered into partnership with UP in 2011 and went 'paper-less' with CHITS by 2012, it already capitalized on PhilHealth reimbursements they received. It was only through Republic Act 10606, National Health Insurance Act of 2013, that a national policy was enacted to encourage use of EMR. Most of UP Manila's partner LGUs are 
now using their PhilHealth Per Family Payment (PFP) to support the maintenance and sustain CHITS.

Technology-Fit. EMRs are known to improve workflow in health facilities, shorten waiting time for patients, and enable faster record retrieval and better access to medical information. ${ }^{30-34}$ In addition, same-day patient-tracing can significantly reduce missed appointments and loss to follow up and improve clinic efficiency. ${ }^{35}$ Documented advantages of EMR to patients are increased satisfaction with the improved quality of health care. ${ }^{36,37}$ There is better patient compliance with health maintenance interventions. ${ }^{38}$ EMR create a safer environment with more accurate medication lists, legible notes and prescriptions, immediately available charts. ${ }^{39}$ Compared to manual registration, there is greater accuracy, higher proportion of correct information. ${ }^{32}$ There are reduced missed appointments and loss to follow up, and waiting time to see providers decreased. ${ }^{31,33}$ EMRs have been proven to be beneficial to health workers: they spend less time for manual recording and paperwork, and are able to finish work much faster, with significant improved accuracy and completeness of data or clinical information. ${ }^{32,36,39,40,41}$ Physicians who use EMR believe that such systems improve quality of care and are generally satisfied with the systems and with the impact of EMR on their work. ${ }^{40,42}$ Similarly, nurses reported positive contribution of EHRs in their work. ${ }^{39,40}$

Two other technology parameters in Rogers' model is exemplified by CHITS: first, it has a relative advantage provides more benefits -- over the paper-based recording and reporting system in terms of decreased time (thus work load) in retrieving patient medical files and preparing FHSIS reports. It affirmed health workers by allowing them to acquire a new and "modern" skill. CHITS is simple and easy to use; it is triable, that is it can be tested and used within their own work desk without having to deal with the numerous cumbersome FHSIS logbooks. The design integrated all the vertical programs of the $\mathrm{DOH}$ into a single user-friendly interface, with drop-down lists, checkboxes and radio buttons to simplify user experience.

CHITS has demonstrated these similar benefits: it has improved operational efficiency, streamlined workflow or transactions in the different areas or workstations in the health center, and aided in defaulter tracking. ${ }^{19}$ It is supported by the local health agency and municipal/city government due to these reasons as well as its social effects on the health professionals and patients as the innovation contributed to building trust and satisfaction with government services.

\section{Challenges and recommended actions}

Despite all the benefits of EMR, challenges to implementation and sustainability remain. In developing countries these are lack of human expertise and financial resource, issues on confidentiality, need for continuing training and support for human resources, and lack of automatic standardization and codifying data entered. ${ }^{20,32}$

In 2012, MHOs of towns that ceased using CHITS cite mainly hardware breakdown problems, many were due to electrical surges in the locale, coupled with lack of local ICT support, and out-migration of RHU health personnel trained on CHITS. ${ }^{19}$ The same HOT-fit framework is applied in the analysis of challenges to CHITS use and adoption.

Technology limitations. Stable electricity is a persistent challenge in developing countries. "In rural health centers that experienced brownouts which in turn led to computer breakdowns, CHITS ultimately failed and the paper-based system proved still to be more effective." 39 Meeting the energy needs of the country is an important requisite to maximize the potentials of eHealth. eHealth in the Philippines cannot develop in isolation of the over-all economic development goals of the Philippine countryside. The World Bank reports that the electrification rate in the country stands at $87.5 \%$ or nearly nine out of ten households out of every 100 have access to electricity, an improvement from the 2013 statistics where 16 million Filipinos did not have access to electricity (overall electrification rate of $83.0 \%$, with urban and rural electrification rate at $94.0 \%$ and $73.0 \%$, respectively). ${ }^{43}$ This is still a long way from the Philippine Development Plan's target of providing electricity to nine out of every ten households by end of 2017. Government infrastructure programs underway are welcome developments for eHealth in the country, but action has to be more urgent.

Because of the physical presence of the UP Manila faculty and students in Pasay City until 2012, technical support to CHITS RHU or facility administrators is maintained even after research funding has ended. For six of these Pasay health centers with internet, technical support is provided via this route. But other RHUs did not have that advantage; many did not contact the NTHC after the typical six-months-period-after training-support has ended, did not have internet-based CHITS support, nor did the NTHC have resources to physically support the RHUs when phone call discussions were insufficient to resolve technical problems. While web-based technologies have the advantage of online support and updates, only a low $29.7 \%$ of Philippine households had access to internet. ${ }^{44}$ Nevertheless, this option is resorted to for the new version of CHITS as this is implemented in the highly urbanized Quezon City and Navotas City. In 2015, the DOST ICT Office launched Juan Konek Digital Empowerment Program that seeks to provide free Wi-Fi Internet connections in 967 poorest municipalities (class 3, 4, 5 and 6) from Luzon to Mindanao, prioritizing low income and underserved communities.

CHITS version 2 is developed and implemented in 89 health facilities currently. Its back end is OpenMRS, deemed by the NTHC to be a more robust system with a more readilyavailable community of software developers who could be 
tapped as CHITS scales to absorb more patient records over time and as it spreads to more health facilities nationwide.

Human factor limitations. One central challenge is an eHealth-enabled cadre of health professionals. The lack of ICT knowledge, reluctance and fear for ICTs among typical middle-aged RHU health workers, coupled with the lack of a dedicated IT for technical support readily available in the locale hinders technology adoption. The WHO Strategy on eHealth recognizes that lack of IT skills and low penetration of ICT in health care institutions are limiting factors in the implementation of eHealth.

To strengthen the Philippine HIS, aside from the UP Manila, other EMR providers address this gap through basic computer skills building among in-service health professionals. The Philippine Commission on Higher Education (CHED) has mandated nursing informatics to be a standard subject in the nursing curriculum. Some medical colleges have also begun to incorporate eHealth and HIS management courses. In the UP College of Medicine, a graduate degree (Master of Science in Health Informatics) is offered and medical students experience hands-on training on the use of CHITS in Pasay Health Centers and the Integrated Surgery Information System in the surgical wards of the Philippine General Hospital as part of patient care. Some can opt to take electives in medical informatics. In CHITS, ethical data management is a cornerstone of the capability building program.

The need for "technical support in the implementation process of the EHR must be emphasized" and the lack of IT personnel within the municipality has become a factor for CHITS abandonment. ${ }^{19,40}$ Since 2012, CHITS implementation thus extended the facility administrator's training module into building local government IT capacities for eHealth systems maintenance using a 'trouble' escalation protocol. Consideration, however, should be given for specific entities to be organized - in the private and non-profit sectors - for such service to be provided to clinics with CHITS, specifically, but all other electronic information systems in general.

eHealth has brought about the need for new skills not only for future health professionals but also allied disciplines of IT, engineering, computer science and even the social and management sciences. The campaign to embed these skills in pre-service and in-service professional education and training should be escalated and systematically addressed.

Organizational limitations. Health information needs are constantly changing, consequently, electronic HIS, such as CHITS need to adapt. With the lack of technical support, who will respond to these needs especially at the local and front lines of health care? CHITS development is dependent on research support from partners, even after over a decade of implementation. CHITS version 2 is in over 200 health facilities already, but support for these is limited within the parameters of the various research projects. By and large, CHITS is a technology ready to be scaled yet without a robust enterprise behind it. The UP Manila is taking steps to address this, organizing a unit separate from the research-based NTHC. In 2012, Philhealth modeled the concept of accreditation of Health IT providers. This can be adopted, but with emphasis on ensuring equity - that GIDA municipalities should also be supported by these Health IT providers.

Premji in 2010 presents her observations on how policy (or the lack thereof) at the health center, local government and national levels supports (or threatens) CHITS expansion and/or sustainability; suggestions remain current (Box 3)..$^{19,45}$

\section{Box 3. Premji 2010}

Several policies had been implemented at the health center level, including one requiring new health center workers to undergo training or be relocated to a non-CHITS health center. Suggested policies at this level included setting a target timeline for when the health center would move from dual, paper and electronic, systems solely to CHITS, as well as a policy requiring health centers to pay for a portion of CHITS so Health center workers become more invested in the system and do whatever is necessary to ensure it becomes sustainable in the long term.

At the local governmental unit (LGU) level, no formal policies had been implemented, although various informal policies were being pursued. Local health offices had allocated internal funding towards CHITS hardware and training, while one health office had also managed to secure external funding for system expansion throughout the jurisdiction. Local in-house technical support people were also identified and were awaiting training on how to network and troubleshoot the system.

Suggested policies involved encouraging a commitment from LGUs to expand CHITS to all health centers within their authority, as results showed that until CHITS was expanded, there would be no impacts at levels higher than the health center. Local health offices were also encouraged to adopt a sustainability plan to ensure that maintenance, funding, technical support and capacity-building issues were addressed once the implementing team withdraws support. Furthermore, there was shared concern among participants that CHITS support be solidified despite political turmoil; in this regard, a policy was suggested that encourages local chief executives to pass an official ordinance that supports CHITS and binds future governments to fund and expand the system.

Several recommendations were discerned from the study findings. Local decision and policy- makers are strongly encouraged to keep in mind that CHITS has tremendous potential to influence how health information is collected, stored and used. Policies must, therefore, be implemented to protect the privacy and security of patient information collection and use. ${ }^{45}$ Furthermore, given that LGUs have independent authority to implement and use CHITS, they have the ability to pass policies that either hinder or encourage CHITS-use between jurisdictions. If CHITS-use is encouraged, the system has the potential to facilitate patient referral systems between different health centers, districts and types of services.

Given the high demand across the Philippines, the implementing team is no longer in a position to effectively shoulder all the responsibilities for CHITS development, installation, training, maintenance, technical support and expansion. More ownership is required from health centers and LGUs, while support from the Department of Health (DOH) is essential if CHITS is to become a sustainable application. Greater manpower is needed to carry out the tasks associated with CHITS, along with secure funding and DOH endorsement that the system is an acceptable alternate data collection tool. Further, without DOH support, electronic or printed reports may never be approved for submission and paper-based logbooks may never be eradicated in support of storing program-specific information in CHITS. 
Electronic Medical Record systems are increasingly being adopted in the Philippines to improve the country's HIS as a building block for better quality patient care and health program management. However, the development and implementation of these systems have gone without standards and guidance resulting in multiple EMR systems without the ability to share patient information when patients move across health facilities and without ability to share selected data specially across various electronic information systems.

In 2010, as the Philippine government changed leaders, these concerns were becoming critical issues as more eHealth innovations are being pilot tested by a growing number of players, efforts of which are also welcomed by an increasing number of local governments sensitized to the benefits of ICTs in health. Thus the DOH convened in 2011 the ICT4Health Technical Working Group (TWG) consisting of representatives from public and private sectors, including the UP Manila as the academic sector representative, and leader in the advocacy for such policy concerns. By 2012, it put forth its recommendations on establishing a nationwide health system enterprise architecture, establishing standards towards interoperability of electronic systems, and on building capacities on eHealth. Further recommended are projects that would demonstrate the adherence of such to the previous three critical components. These ICT4Health TWG recommendations are expected to be favorable to sustain and scale CHITS. Action by the DOH is awaited, especially to continue this multi-sectoral engagement in national eHealth development towards Universal Health Care.

\section{Conclusion}

CHITS was developed through a collaborative, participatory user-centric strategies that allowed engagement of health workers to test and embrace a new way of health data management. Participatory and modular training supported the health workers throughout the adoption of the innovation. CHITS, as a technology, met the everyday needs of the local health workers primarily and the central government, secondarily. Increased efficiency, improved data quality, streamlined records management and improved morale among government health workers are benefits attributed to CHITS; these reinforce use and encourage others to adopt the system. Its longevity and expansion through peer and local policy adoption speaks of an eHealth technology built for and by the people.

Effective change management is crucial in the success of transition from paper-based system to an electronic HIS. While computerization has been adapted by an increasing number of local governments, needs of end-users, program managers and policy-makers continue to evolve. Lack of standards hampers meaningful data exchange and use across different information systems. Since health service delivery is devolved, RHUs (oftentimes with the support of development partners) have taken the initiative to seek out CHITS, or other EMRs. The diversity is good - to cull unique lessons and define what works - at the early stages of innovation. But at present setting standards is now an urgent concern to stem the emerging islands of data; interoperability of electronic information systems, even across sectors have to be addressed.

Challenges in keeping CHITS technically robust, up-todate and scalable are already encountered. UP NTHC has to address concerns of maintenance and continuous development of CHITS to support RHUs who have adopted CHITS. Ensuring a cadre of eHealth-enabled health workers is also a need.

eHealth in the Philippines cannot develop in isolation of the over-all development goals of the country. Provision of basic utilities such as electricity in the countryside is fundamental and has to be hastened. Connectivity will also further the progress of underserved communities. Government has primary responsibility over this for Filipinos to truly experience the benefits of innovations in science and technology.

Policy and operational gaps identified in this study have to be addressed using truly people-centric perspective and participatory strategies but with urgency in order to meet Kalusugang Pangkalahatan targets.

Strong leadership and governance are critical factors in determining the success or failure of CHITS or any eHealth innovation for that matter. A national eHealth governance body is warranted to set clear directions, regulate expensive ICT and eHealth investments and ensure these contribute to national health and development efforts.

\section{Post Script}

In the last quarter of 2013, the National eHealth Steering Committee (NeHSC) was organized, co-chaired by Secretaries of the DOH and DOST along with the UP Manila Chancellor and heads of offices of PhilHealth and CHED. The NeHSC is the Philippine's national governance body that sets the direction for eHealth development and implementation to meet health and development goals. Its creation is guided by the Philippine national eGovernment Master Plan as well as the WHO - International Telecommunications Union National eHealth Strategy Toolkit. The NeHSC developed the Philippine National eHealth Strategy through multisectoral consultations; it's first major project is the Philippine Health Information Exchange (HIE). Technical Experts Groups (from public and private sectors) on Health Data Standards and Health Data Privacy, among others, have been organized in order to set fundamental policy on the eHealth in the country. The NeHSC recently published in January 2016 the Joint Administrative Orders on the Philippine HIE as well as its Guidelines on Health Data Privacy. 
By December 2015, the new version of CHITS has been disseminated to 230 health facilities nationwide through support of various government and non-government agencies. PhilHealth and DOH recently certified CHITS, along with the five other EMR, to be platforms that can electronically provide documentation of primary care benefits services rendered by an RHU (PhilHealth Advisory 11-01-2015). Health facility EMR should then be able to exchange specific information through the Philippine HIE. This is envisioned to allow secure, seamless exchange of health data among health institutions, including those where CHITS is used - to ensure continuity of patient care, and more efficient payment of benefits due to health facilities providing services to the Filipino. Further rigorous research studies need be done to evaluate whether CHITS in these sites have significant effects on public health program management and decisions, and on clinical outcomes. Researches on additional innovative features of CHITS are ongoing.

\section{References}

1. Rustagi N, Singh R. Electronic medical record: Time to migrate? [Online]. 2012 [cited 2013 June]. Available from https://www.ncbi. nlm.nih.gov/pmc/articles/PMC3530982.

2. Segworks Technologies Corporation. Your open source and business software specialist [Online]. 2012 [cited 2012 June]. Available from http://segworks.org.

3. Bizbox Com TM Group [Online]. 2012 [cited 2012 June]. Available from http://bizbox.com.

4. Smart Communications Inc [Online]. 2012 [cited 2012 June]. Available from http://smart.com.ph/corporate.

5. Wireless Access for Health. Technology for Happier, Healthier Communities [Online]. 2012 [cited 2012 June]. Available from http://wah.ph.

6. Medicus Mundi International Network. Health Information [Online]. 2013 [cited May 2014]. Available from http://www.medicusmundi. org/en/topics/health-information.

7. Tolentino HD, Marcelo AB. Community Health information and Tracking System. Dougherty, M. Exploring New Modalities: Experiences in Information and Communications Technology Interventions in the Asia-Pacific Region. Bangkok, Thailand: UNDP Asia-Pacific Development Information Program. 2006; 124-5.

8. Marcelo P. Partnership Matters: Lessons from a Decade of CommunityUniversity Collaboration in Community and Local Health Systems Development. Urban Community Health Program \& University of the Philippines - College of Medicine. 2010; 171-86.

9. Department of Health. Speeches of Secretary Ona [Online]. 2010 [cited May 2014]. Available from http://www.doh.gov.ph/secretary_ speeches.html.

10. Department of Health. Achieving Universal Health Care: 2010 Annual Report [Online]. 2010 [cited 2011 June]. Available from http://www.doh. gov.ph/sites/default/files/ DOH\%20AR\%2010\%20NOV23\%20edited.pdf.

11. Yusof MM, Kuljis J, Papazafeiropoulou A, Stergioulas LK. An evaluation framework for Health Information Systems: human, organization and technology-fit factors (HOT-fit). Int J Med Inform. 2008; 77(6):386-98.

12. Heeks R, Mundy D, Salazar A. Why Health Care Information Systems Succeed or Fail, Working Paper Series: Information Systems for Public Sector Management [Online]. 1999 [cited 2012 June]. Available from http://www.sed.manchester.ac.uk/idpm/research/publications/wp/igovern ment/documents/igov_wp09.pdf.
13. Tolentino H, Marcelo A, Marcelo P, Maramba I. Linking primary care information systems and public health vertical programs in the Philippines: an open-source experience. AMIA Annu Symp Proc. 2005; 311-15.

14. National Telehealth Center CHITS Navotas Inception Report 2011. 2012.

15. OpenMRS Inc [Online]. 2012 [cited 2012 June]. Available from http://openmrs.org/.

16. Catangui M, Gavino R, Ongkeko A, et al. Baseline Studies for CHITSOpenMRS in Navotas, Quezon City, Gamay, Glan and Santo Domingo. 2012.

17. FGD with Malibay and Lagrosa Health Center Staff. 31 May 2012.

18. National Telehealth Center. CHITS Technical Reports 2011-2012. Unpublished.

19. Premji S, Casebeer A, Scott R. Implementing Electronic Health Information Systems in Local Community Settings: examining Individual and Organisational change experiences in the Philippines. EJISE. 2012; 15(2):186-97.

20. Williams F, Boren SA. The role of the electronic medical record (EMR) in care delivery development in developing countries: a systematic review. Inform Prim Care. 2008; 16(2):139-45.

21. Lacbawan LN. Patient Perceptions of EHR and CHITS Technology on delivery of care in Pasay City, Metro Manila, Philippines. Department of Global Health School of Public Health and Health Services in The George Washington University Washington, D.C., USA. 2011.

22. Thomas B, Jone P, et al. Student Perceptions of Effective E-moderation: A Qualitative Investigation of E-College Wales. Networked Learning Conference. Lancaster University, England. 2004; 04.

23. Kaplan B, Harris-Salamone KD. Health IT success and failure: recommendations from literature and an AMIA workshop. J Am Med Inform Assoc. 2009; 16(3):291-9.

24. Tolentino H, Marcelo A, Marcelo P, et al. The Evolution of a Community Based Child Injury Surveillance Project: Lessons from the Ground [Online]. 2006 [cited 2014 Jan]. Available from http://www.amic.org.sg/Resources/Research_Materials/media_and_ health/The $\% 20$ Evolution $\% 20$ of $\% 20$ a $\% 20$ Community $\% 20$ Based $\% 20$ Child\%20Injury\%20Surveillance\%20Project.pdf.

25. Dictionary.com. Predisposition [Online]. 2002 [cited 2014 April] Available from http://dictionary.reference.com/browse/predisposition.

26. The Free Dictionary. Reinforce [Online]. 2003 [cited 2014 April]. Available from http://www.thefreedictionary. com/reinforce.

27. Versoza J, Ian R, Vidallon B, et al. An Evaluation of CHITS Users Behaviors on Selected Health Centers in Pasay City, Metro Manila. University of Santo Tomas College of Nursing. 2010.

28. Rogers, Everett M. Diffusion of Innovations, $4^{\text {th }}$ Edition. Simon and Schuster: 2010.

29. Montalban J, Mejor F. Evaluation of a Primary Care Computerized Information System as a Monitoring Tool for Utilization of the Outpatient Benefits of the Philippine National Health Insurance Program in Selected Health Centers in a Metropolitan Area, $2^{\text {nd }}$ ed. 2010; 154-70.

30. Linder JA, Schnipper JL, Tsurikova R, Melnikas AJ, Volk LA, Middleton B. Barriers to electronic health record use during patient visits. AMIA Annu Symp Proc. 2006:499-503.

31. Diero L, Rotich JK, Bii J, et al. A computer-based medical record system and personal digital assistants to assess and follow patients with respiratory tract infections visiting a rural Kenyan health centre. BMC Med Inform Decis Mak. 2006; 6:21.

32. Tomasi E, Facchini LA, Maia MF. Health information technology in primary health care in developing countries: a literature review. Bull World Health Organ. 2004; 82(11):867-74.

33. Garrido T, Jamieson L, Zhou Y, Wiesenthal A, Liang L. Effect of electronic health records in ambulatory care: retrospective, serial, cross sectional study. BMJ. 12 Mar 2005;330(7491):581.

34. Levesque Y. Going Paperless with Minimal Pain [Online]. 2001 [cited 2014 June]. Available from http://www.chmonline.ca/issue/article. jsp?content.

35. Alamo ST, Wagner GJ, Sunday P, et al. Electronic Medical Records and Same Day Patient Tracing Improves Clinic Efficiency and Adherence to Appointments in a Community Based HIV/AIDS Care Program. Uganda: AIDS Behav. 2011. 
36. Joos D, Chen Q, Jirjis J, Johnson KB. An electronic medical record in primary care: impact on satisfaction, work efficiency and clinic processes. AMIA Annu Symp Proc. 2006; 394-8.

37. Irani JS, Middleton JL, Marfatia R, Omana ET, D'Amico F. The use of electronic health records in the exam room and patient satisfaction: a systematic review. J Am Board Fam Med. 2009; 22(5):553-62.

38. Jerant AF, Hill DB. Does the use of electronic medical records improve surrogate patient outcomes in outpatient settings? J Fam Pract. 2000; 49(4):349-57.

39. Galimany Masclans J, Garrido Aguilar E, Roca Roger M, Girbau García MR. New Technologies and Nursing. Use and perception of primary health care nurses about electronic health record. Rev Enferm. 2012; 35(9):42-5.

40. Likourezos A, Chalfin DB, Murphy DG, Sommer B, Darcy K, Davidson SJ. Physician and Nurse Satisfaction with an Electronic Medical Record System. J Emerg Med. 2004; 27(4):419-24.
41. Douglas GP, Deula RA. Improving the completeness and accuracy of health information through the use of real-time data collection at the point of care [Online]. 2003 [cited 2013 June]. Available from http://www.dbmi.pitt.edu/sites/ default/files/u6/Helina_2003.pdf.

42. DesRoches CM, Campbell EG, Rao SR, et al. Electronic health records in ambulatory care--a national survey of physicians. N Engl J Med. 2008; 359(1):50-60.

43. Felongco, G. Nine out of ten Philippine households to have electricity by 2017. Gulf News Philippines [Online]. 2016 [cited 2016 Jan]. Available from http://gulfnews.com/ news/asia/philippines/nine-out-of-tenphilippine-households-to-have-electricity-by-2017-1.1661577.

44. International Telecommunication Union. Philippines: ICT Facts and Figures 2010 [Online]. 2010 [cited 2012 June]. Available from http://www.itu.int/en/ITU-D/Statistics/ Pages/facts/default.aspx.

45. Republic Act No. 10173, the Data Privacy Act. August 15, 2012.

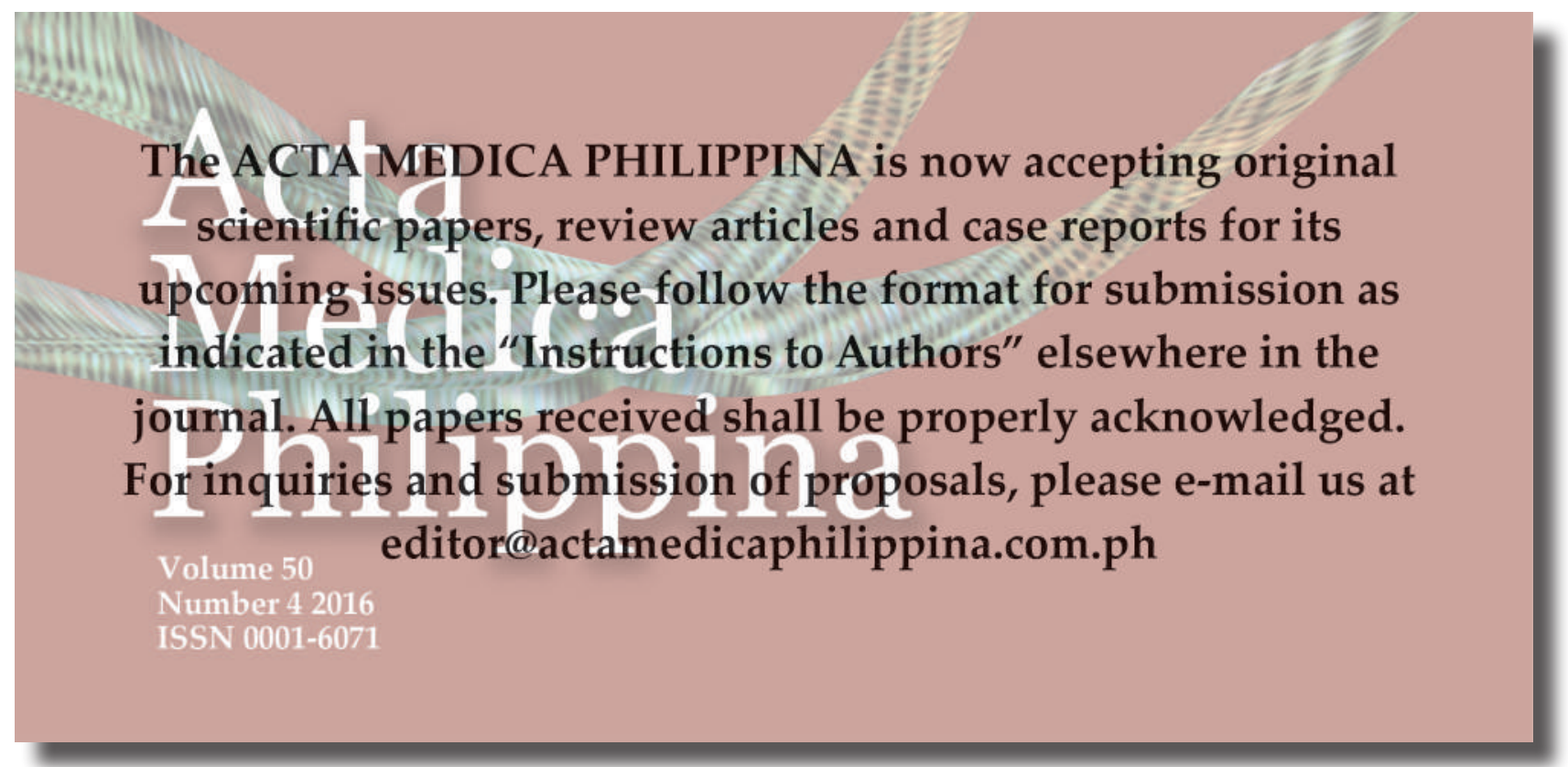

